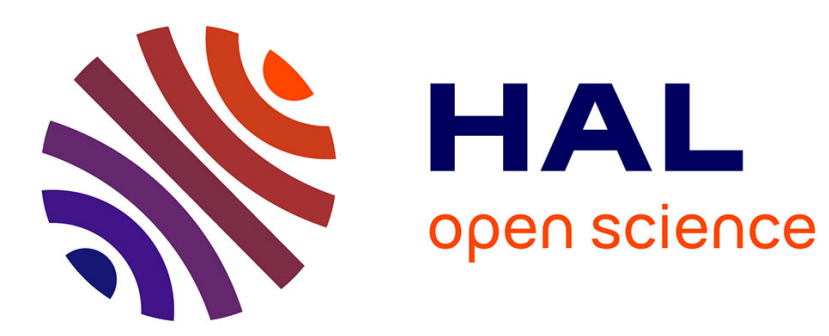

\title{
Dynamics of ions in a water drop using the AMOEBA polarizable force field
}

Florian Thaunay, Gilles Ohanessian, Carine Clavaguera

\section{To cite this version:}

Florian Thaunay, Gilles Ohanessian, Carine Clavaguera. Dynamics of ions in a water drop using the AMOEBA polarizable force field. Chemical Physics Letters, 2017, 671, pp.131-137. 10.1016/j.cplett.2017.01.024 . hal-01999944

\section{HAL Id: hal-01999944 https://hal.science/hal-01999944}

Submitted on 5 Feb 2019

HAL is a multi-disciplinary open access archive for the deposit and dissemination of scientific research documents, whether they are published or not. The documents may come from teaching and research institutions in France or abroad, or from public or private research centers.
L'archive ouverte pluridisciplinaire HAL, est destinée au dépôt et à la diffusion de documents scientifiques de niveau recherche, publiés ou non, émanant des établissements d'enseignement et de recherche français ou étrangers, des laboratoires publics ou privés. 
Research paper

\title{
Dynamics of ions in a water drop using the AMOEBA polarizable force field
}

\author{
Florian Thaunay, Gilles Ohanessian, Carine Clavaguéra* \\ LCM, CNRS, Ecole Polytechnique, Université Paris Saclay, 91128 Palaiseau, France
}

\section{A R T I C L E I N F O}

Article history:

Received 13 October 2016

In final form 10 January 2017

Available online 12 January 2017

\section{Keywords:}

Ion hydration

Molecular dynamics

Polarizable force field

Coordination number

Residence time

Water cluster

\begin{abstract}
A B S T R A C T
Various ions carrying a charge from -2 to +3 were confined in a drop of 100 water molecules as a way to model coordination properties inside the cluster and at the interface. The behavior of the ions has been followed by molecular dynamics with the AMOEBA polarizable force field. Multiply charged ions and small singly charged ions are found to lie inside the droplet, while bigger monovalent ions sit near the surface. The results provide a coherent picture of average structural properties as well as residence times for which a general trend is proposed, especially for the anions.
\end{abstract}

(c) 2017 Elsevier B.V. All rights reserved.

\section{Introduction}

Understanding the dynamics of simple ions dissolved in water may have wide applications in inorganic chemistry, biological environment or atmospheric chemistry [1]. The approaches to study the ion solvation mechanisms are multiple, both experimental and theoretical. In solution, an ion deconstructs locally the water network, and the competition between water-ion and water-water interactions reflects the ability of the ion to organize molecules around it. These interactions have been studied for a long time and are symbolized by the Hofmeister series which turned out to reflect trends in several properties of hydrated ions, besides their ability to precipitate proteins [2]. Nowadays, the effect of ions on the structuration of water can be measured by different spectroscopic techniques such as NMR, neutron and X-ray diffraction, X-ray absorption spectroscopy, infrared and Raman spectroscopy. Gas-phase experiments are also available to study a single ion in an isolated water drop without the effect of the environment such as counterions. Indeed, high pressure mass spectrometry [3] and threshold collision-induced dissociation [4] were used to obtain hydration energies for a broad set of hydrated ions. Furthermore, vibrational predissociation spectra have been obtained for water clusters in a larger size range of tens to hundreds of molecules, incorporating diverse ions with charges from

\footnotetext{
* Corresponding author.

E-mail addresses: gilles.ohanessian@polytechnique.edu (G. Ohanessian), carine. clavaguera@polytechnique.edu (C. Clavaguéra).
}

-2 to +3 [5-7]. This size range provides adequate models to understand the fundamental ability of an ion to structure its first two hydration shells. Such experiments yield IR action spectra; thus structural information can only be inferred indirectly and remains rather limited. Our aim is to devise a simulation approach which is able to bridge this gap, yielding structural as well as spectroscopic information. In the present work, we use structural data derived from experiment in bulk solution to assess this model's accuracy. Comparison to experimental IR spectra will be reported separately.

From a theoretical point of view, micro-hydrated ions have been generally considered using static quantum chemical calculations [8]. However, a dynamical behavior is only obtained from molecular dynamics (MD) simulations that can be either DFT MD $[9,10]$ or classical MD [11]. Both methods have been used in condensed phase or at the liquid/vapor interfaces to compute ion hydration properties [12]. Average structural properties and water residence around the ion usually require simulations in the nanosecond range to get reliable values. Consequently, DFT MD cannot provide an appropriate description due to the limitation in the simulation time. MD simulations based on classical force fields have been widely used to model ion hydration and have been improved to treat multicharged ions [11,13-16].

The divalent cations $\mathrm{Mg}^{2+}$ and $\mathrm{Ca}^{2+}$, as well as $\mathrm{Na}^{+}$, are known to be strongly hydrated ions with a structuring effect on at least their first two solvation shells $[11,12,17]$ whereas for larger monovalent cations (such as $\mathrm{K}^{+}$and $\mathrm{Cs}^{+}$) or polyatomic ions (such as tetramethylammonium), water-water interactions are often stronger than ion-water interactions [18]. The behavior of anions has 
been largely debated both by experimentalists and theorists. Experiments on very small clusters $(n \leqslant 6)$ established the presence of $\mathrm{Cl}^{-}, \mathrm{Br}^{-}$and $\mathrm{I}^{-}$at the surface [5,19]. Ab initio calculations on small clusters predicted $\mathrm{F}^{-}$inside and the other halides at the surface $[12,20]$. The differences in the solvation process for $\mathrm{F}^{-}$ and $\mathrm{Cl}^{-}$in small (4-20 molecules) water clusters have been studied by classical MD indicating a fully solvated $\mathrm{F}^{-}$vs. only a partially solvated $\mathrm{Cl}^{-}$[21]. Conversely, Dang et al. concluded to the presence of both $\mathrm{F}^{-}$and $\mathrm{Cl}^{-}$at the surface of small water clusters with 1-6 molecules by polarizable MD simulations [22].

For larger systems, particularly in the case of bulk liquid/vapor interfaces, the behavior of halides may be different because the curvature of the surface can play an important role and promote complete solvation of the ions. Tobias et al. combined results from experiments and MD simulations on $\mathrm{NaCl}$ aerosols [23]. Experimentally, they irradiated aqueous $\mathrm{NaCl}$ aerosols to create $\mathrm{OH}$ radicals, and then, observed chlorine production at the interface, suggesting a wide presence of chloride ions close to the surface. In MD simulations, they used different force fields and a wide range of system sizes, and concluded that $\mathrm{Cl}^{-}$remains mainly close to the interface. Then, they carried out numerous polarizable MD simulations to compare the mobility of various anions and cations [24]. They concluded that the smallest ions, i.e. $\mathrm{F}^{-}, \mathrm{Na}^{+}, \mathrm{OH}^{-}$, move away from the surface while the largest ones $\left(\mathrm{H}_{3} \mathrm{O}^{+}, \mathrm{NO}_{3}^{-}, \mathrm{Cl}^{-}, \mathrm{Br}^{-}\right.$, $\mathrm{I}^{-}$) remain at the surface, with a more pronounced effect for $\mathrm{Br}^{-}$ and $\mathrm{I}^{-}$. In several computational studies, the influence of the force field on the results has been pointed out, especially the role of an explicit inclusion of many-body effects in the simulations $[11,25,26]$. For example, a strong energetic stabilization due to polarization effects has been highlighted for halide hydration [27].

We propose here a systematic study of various ions in a water drop of 100 molecules by classical molecular dynamics based on the polarizable AMOEBA force field [28]. The ions considered, $\mathrm{La}^{3+}, \mathrm{Ca}^{2+}, \mathrm{Li}^{+}, \mathrm{Na}^{+}, \mathrm{K}^{+}, \mathrm{Cs}^{+}, \mathrm{F}^{-}, \mathrm{Cl}^{-}, \mathrm{Br}^{-}, \mathrm{SO}_{4}^{2-}$, are both cations and anions, carrying a charge ranging from -2 to +3 . The same force field, which includes an explicit polarization term and a high level electrostatic representation, is used for all cases to provide a coherent overview of their structural and dynamics properties. The behavior of the ions in the cluster is followed during relatively long simulations and the residence time of the water molecules in the first coordination shell is evaluated through a model of persisting coordination as proposed in the literature [12].

\section{Simulation details}

In recent years, the AMOEBA polarizable force field has been successfully used to determine the structural and thermodynamic properties of various ions in solution such as $\mathrm{K}^{+}, \mathrm{Na}^{+}$and $\mathrm{Cl}^{-}$in liquid water and formamide [29], halides at the water/vapor interface [30], hydration of divalent cations $\left(\mathrm{Ca}^{2+}, \mathrm{Mg}^{2+}[15], \mathrm{Zn}^{2+}[14,31]\right.$ and $\mathrm{Fe}^{2+}$ [13]) and lanthanide and actinide cations [32]. The two major features of the AMOEBA force field are an explicit inclusion of polarization effects using a self-consistent atomic dipole polarization procedure, and a multipolar expansion up to quadrupoles on each atom to represent the electrostatic interactions.

In 2003, Ren and Ponder released the 03-version of their AMOEBA polarizable force field for water [28]. This water model was able to reproduce various gas phase data of water clusters and liquid phase properties of pure water. In this study, we used available ion parameters from the literature which have been obtained mainly to reproduce ion-water interactions using the AMOEBA03 water force field. Accordingly, the simulations have been performed with this 03-version. For the intermolecular parameters, each atom has 2 parameters for the buffered 14-7 repulsion-dispersion term, an atomic charge and polarizability. Furthermore, a polarization-damping scheme is used via a smeared charge distribution as proposed by Tholé [28]. It was proven previously that this damping factor, initially at 0.39 for water and single charged ions, should be decreased for multicharged ions $[14,15,32]$. In addition in the case of the sulfate ion, a multipole distribution was obtained for $\mathrm{S}$ and $\mathrm{O}$ atoms. The parameters used are provided in Table S1 in Supplementary Material.

The simulations were carried out with the TINKER 6 software [33]. The trajectories were propagated using the velocity-Verlet al gorithm with a $1 \mathrm{fs}$ time step. The minimum simulation time was $10 \mathrm{~ns}$, up to $20 \mathrm{~ns}$ for anions. The initial geometry of the drop with 100 water molecules was taken as that of an experimentally observed symmetrical cluster bearing a central cavity [34]. Simulations were started from two different initial configurations, with the ion ( - II to +III charged) inside, i.e. structure called Ion-Int, or on the surface, i.e. Ion-Ext, of the water cluster. In the first case, the ion was positioned at the center of the cage, followed by an AMOEBA geometry optimization. For the second case, one needs realistic starting structures, i.e. with a representative water network, for both positive and negative ions. During the simulations with $\mathrm{F}^{-}$and $\mathrm{Ca}^{2+}$ initially inside the drop, the ions approached the surface and provided adequate starting structures for an IonExt simulation, which were used for all other ions. We noted that the AMOEBA geometry optimization can deform the initial structure, even for the Ion-Int structure, especially when the ion is large and multiply-charged (Fig. 1).

The ion coordination numbers were obtained from the radial distribution function of ion-O pairs. They can be compared to available experimental values to check the cluster model ability to reproduce the competitive ion-water and water-water interactions. Residence times of a water molecule in the first coordination sphere of the ion were computed from the model of persisting coordination proposed by Impey et al. [35]. A parameter $t^{*}=2 \mathrm{ps}$ was used to consider a temporary migration of a water molecule away from the first coordination sphere.

The temperature was set to $200 \mathrm{~K}$, maintained using the NoseHoover thermostat, to be in the same range than the gas phase experimental temperature [18]. In order to avoid evaporation of water molecules during the dynamics, a spherical van der Waals potential encloses the cluster with a $12 \AA$ radius. At this temperature, evaporation "attempts" occur on average less than once per simulation of $10 \mathrm{~ns}$, therefore the impact of the van der Waals wall is negligible. Furthermore, it was shown that in MD simulations, the mobility of water molecules is larger than experimentally at the same temperature and the correspondance between experimental and computed temperature is questionable [36].

\section{Results and discussion}

\subsection{Validation of the force field}

In the AMOEBA force field, the available ion parameters have been validated on bulk hydration properties, such as coordination numbers, average water-ion distances in each coordination shell, or solvation free energies. The goal of this study is to simulate the dynamics of ions in a 100-water drop, however no structural properties are available experimentally for a direct comparison. Nevertheless, these properties can be compared with bulk data as a safeguard for the simulations. Table 1 presents the mean number of water molecules in the first and second shells obtained from the simulations for the various ions, together with available experimental values in solution. Globally, the computed values are in the experimental range. For example for $\mathrm{La}^{3+}$, the $\mathrm{CN}$ remains at 9 with an average La-O distance of ca. $2.51 \AA$ which both agree with 

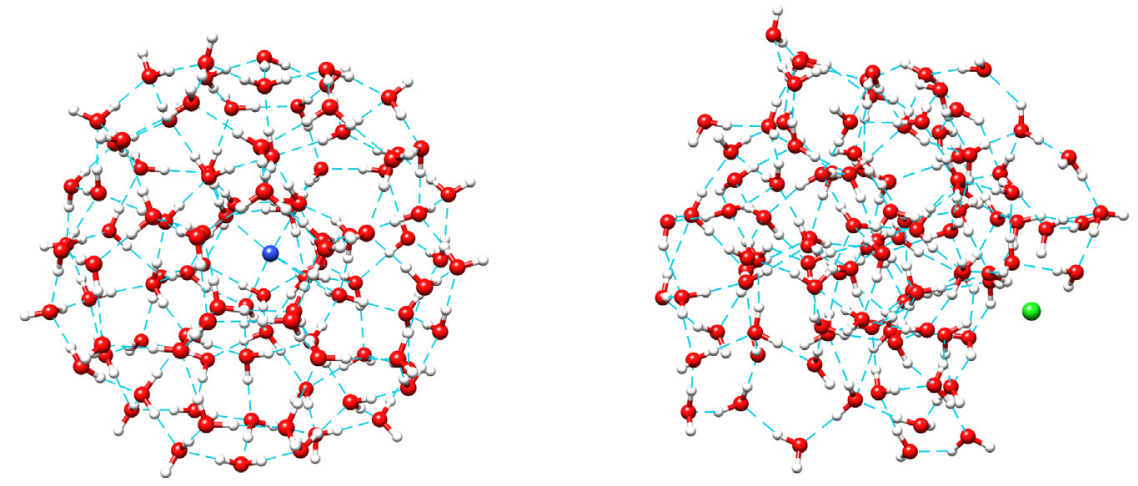

Fig. 1. On the left side, Ion-Int optimized starting structure for $\mathrm{Na}^{+}$, and on the right side, Ion-Ext optimized starting structure for $\mathrm{Cl}^{-}$.

Table 1

Coordination numbers and number of water molecules in the second shell in comparison with available experimental data.

\begin{tabular}{|c|c|c|c|c|c|c|}
\hline \multirow[t]{3}{*}{ Ions } & \multicolumn{2}{|c|}{ EXP } & \multicolumn{4}{|c|}{ AMOEBA } \\
\hline & \multirow[t]{2}{*}{ 1st Sh. } & \multirow[t]{2}{*}{ 2nd Sh. } & \multicolumn{2}{|c|}{ 1st Sh. } & \multicolumn{2}{|c|}{ 2nd Sh. } \\
\hline & & & Av. & Var. & Av. & Var. \\
\hline $\mathrm{La}^{3+}$ & $9.0^{\mathrm{a}}$ & $18^{\mathrm{a}}$ & 9.0 & 9.0 & 18.8 & $17.1-20.6$ \\
\hline $\mathrm{Ca}^{2+}$ & $8.0^{\mathrm{b}}$ & $17^{\mathrm{b}}$ & 8.0 & $7.6-8.3$ & 17.7 & $15.7-19.9$ \\
\hline $\mathrm{Li}^{+}$ & $4^{c}$ & $12^{\mathrm{d}}$ & 4.4 & $3.4-5.4$ & 13.9 & $11.4-16.1$ \\
\hline $\mathrm{Na}^{+}$ & $4-8^{c}$ & & 5.9 & $5.1-6.5$ & 16.8 & 13.9-19.6 \\
\hline $\mathrm{K}^{+}$ & $4-6^{c}$ & & 6.2 & $5.5-7.4$ & 16.2 & $12.6-19.9$ \\
\hline $\mathrm{Cs}^{+}$ & $6-8^{c}$ & & 7.9 & $6.4-9.4$ & 18.1 & $13.9-22.2$ \\
\hline $\mathrm{F}^{-}$ & $4-6^{c}$ & & 5.9 & $5.2-6.6$ & 17.9 & $13.0-23.0$ \\
\hline $\mathrm{Cl}^{-}$ & $5-6^{c}$ & & 5.0 & $3.7-6.2$ & 11.8 & $8.3-15.2$ \\
\hline $\mathrm{Br}^{-}$ & $6^{c}$ & & 5.0 & $4-6$ & 11.7 & $8.0-15.4$ \\
\hline $\mathrm{SO}_{4}^{2-}$ & $12^{\mathrm{e}}$ & & 12.2 & $11.2-13.1$ & 24.7 & $18.7-29.5$ \\
\hline
\end{tabular}

a [37].

b $[15,39]$.

c [36].

d [44].

e $[45,46]$.

experimental data (9.0 and 2.52-2.62 Å, respectively [16,37]). The experimental $\mathrm{CN}$ of $\mathrm{Ca}^{2+}$ is known to be strongly dependent on the concentration with an average value of ca. 8 for low concentration [38] in agreement with the computed $\mathrm{CN}$ of 8.0. For both cations, the number of water molecules present in the second sphere are close to the experimental numbers of ca. 17 for $\mathrm{Ca}^{2+}$ [39] and 18 for $\mathrm{La}^{3+}$ [37]. Similar conclusions can be drawn for the other cations and the anions. These results lend support to the use of the AMOEBA parameters to follow the behavior of the ions in the drop.

\subsection{Water exchanges}

The residence time of a water molecule in the first coordination sphere of an ion is related to the strength of the ion-ligand interactions and can be used to estimate the ion structuring ability. While experimental data for the cations are available, data for anions are scarce. The residence times have been computed for the various ions under study and are provided in Table 2 . Since the cluster approach is likely to introduce some distorsion to residence times as measured in the bulk, our discussion is mainly qualitative, limited to orders of magnitude and trends within ion series.

For $\mathrm{Ca}^{2+}$ and $\mathrm{La}^{3+}$, the residence time is ca. few nanoseconds and consequently, the simulations showed only few exchanges and no exchange, respectively. Regarding the monovalent cations, the residence time decreases from $\mathrm{Li}^{+}$to $\mathrm{Cs}^{+}$(even if the difference
Table 2

Water molecule residence times (in ns) in the first solvation shell of the ions.

\begin{tabular}{lll}
\hline Ions & Experiments & AMOEBA Int/Ext \\
\hline $\mathrm{F}^{-}$ & & $1.71 / 1.17$ \\
$\mathrm{Cl}^{-}$ & & $0.43 / 0.75$ \\
$\mathrm{Br}^{-}$ & & $0.08 / 0.64$ \\
$\mathrm{Li}^{+}$ & $2.37[47]$ & $2.60 / 3.20$ \\
$\mathrm{Na}^{+}$ & $1.25[47]$ & $3.08 / 2.35$ \\
$\mathrm{~K}^{+}$ & $0.81[47]$ & $0.66 / 0.58$ \\
$\mathrm{Cs}^{+}$ & $0.28[47], 0.2[48], 0.1[49]$ & $0.27 / 0.44$ \\
$\mathrm{Ca}^{2+}$ & $2.96[47], \sim 10[49]$ & Few exchanges \\
$\mathrm{La}^{3+}$ & $4.8[47], \sim 10[49]$ & No exchange \\
\hline
\end{tabular}

between $\mathrm{Li}^{+}$and $\mathrm{Na}^{+}$is not straightforward). In the latter case, the computed time from the inside starting point is twice as small as that for the starting point at the cluster surface due to the large fluctuation in the number of first neighbours (Fig. 4).

For anions, the dynamics is slower from $\mathrm{I}^{-}$to $\mathrm{Br}^{-}$and $\mathrm{Cl}^{-}$with times in the range of tens of picoseconds [40]. Laage and Hynes performed MD simulations in periodic boundary conditions using both polarizable and non polarizable models for water, and proposed several models to determine water residence time for halides from 5 to 10 ps with the polarizable model [41]. The residence times extracted from the present cluster approach simulations are larger in magnitude but the order is preserved from $\mathrm{F}^{-}$ to $\mathrm{Br}^{-}$. For $\mathrm{Br}^{-}$cases, the times obtained are very different in the 
two simulations. As they naturally prefer to be at the cluster surface, the organization of the water molecules around the ion and their mobility are indeed disturbed.

\subsection{Dynamical behavior}

For each ion, the results are gathered in a series of six graphs, as shown in Figs. 2, 4 and 5 for $\mathrm{La}^{3+}, \mathrm{Cs}^{+}$and $\mathrm{Cl}^{-}$, respectively. The figures concerning the other ions are available in Supplementary Material (Figs. S2-S8). The time evolution of various properties is followed starting with Ion-Ext and Ion-Int structures on the left and right side, respectively. The upper panel displays the time evolution of the distance between the ion and the center of mass of the drop. The initial distance varies depending on the localization of the ion and the result of the initial geometry optimization. This distance cannot confirm by itself if the ion is present at the surface or within the cluster. However, in the cases where the drop remains essentially spherical, one can easily correlate distance ranges with ion positions. Indeed, the diameter of the spherical cluster being ca. $17 \AA$, the distances of the ion to the center of mass can be naturally distributed as follows: $\leqslant 5-6 \AA$ for a complete double solvation shell with the ion inside the drop, ca. $6 \AA$ for an incomplete second shell, and ca. 7-8 $\AA$ for an ion at the surface. The middle and lower panels in the figures monitor the coordination number (first neighbours) and the number of second neighbours of the ions, respectively, as a function of time. The boundaries of the coordination spheres are obtained from the radial distribution functions computed over the simulations (Fig. S1).

$\mathrm{La}^{3+}$ and $\mathrm{Ca}^{2+}$ carry the highest positive charges, and they have a similar structuring behavior of the water drop for the simulations starting both from an ion at the surface or in the center of the cluster (Figs. 2 and S2). The high charge leads to strong interaction with the molecules in the first shell and the cation clearly favors an internal position with a $\mathrm{CN}$ of 9.0 for $\mathrm{La}^{3+}$ and 8.0 for $\mathrm{Ca}^{2+} \cdot \mathrm{La}^{3+}$ has the largest $\mathrm{CN}$ and this very strong effect in the first shell was only observed for lanthanum; it was already highlighted by Bowron et al. to explain the sharp break in the aqueous solvent structure (in the bulk for $\mathrm{LaCl}_{3}$ molar solutions) by the high coordination number of 9 and the tricapped trigonal prism arrangement around $\mathrm{La}^{3+}$ [42]. The structuring effect is also present in the second solvation shell for both cations, with a limited variation of the number of water molecules between 16 and 20. The final structures for both calcium simulations remain relatively spherical (Fig. 3). This observation correlates with the Hofmeister series in which $\mathrm{Ca}^{2+}$ is one of the most chaotropic ions.

In comparison with the previous cases, the alkali metal ions are considered to be relatively poorly solvated, and their coordination strongly depends on the size of the cation and the concentration of the solution. $\mathrm{Li}^{+}$is the smallest cation of the series and despite its single charge, it remains solvated by two shells of water in the major part of the simulations. When the starting point corresponds to the ion outside the drop, the fluctuation of the distance between the ion and the center of mass of the aggregate is small. For the inside starting point case, the ion spends few nanoseconds outside before stabilizing inside the drop. The mean $\mathrm{CN}$ is 4.4 (see fluctuations between 4 and 5 first neighbours in Fig. S3) with an average Li-O distance of $2.04 \AA$ in the first shell. The second sphere is also well structured with ca. 14 water molecules for the simulation time during which the cation is stable inside the drop.

With increasing cation size, from $\mathrm{Na}^{+}$to $\mathrm{K}^{+}$and then $\mathrm{Cs}^{+}$, a progressive reduction of the structuring power of the ion is observed during the simulations as expected from the Hofmeister series. $\mathrm{Na}^{+}$has also a global solvating behavior. When the starting point corresponds to the ion at the surface of the cluster, 2 ns are necessary for the cation to migrate inside. Furthermore, $\mathrm{Na}^{+}$remains mainly solvated as for the inside starting point simulation. The
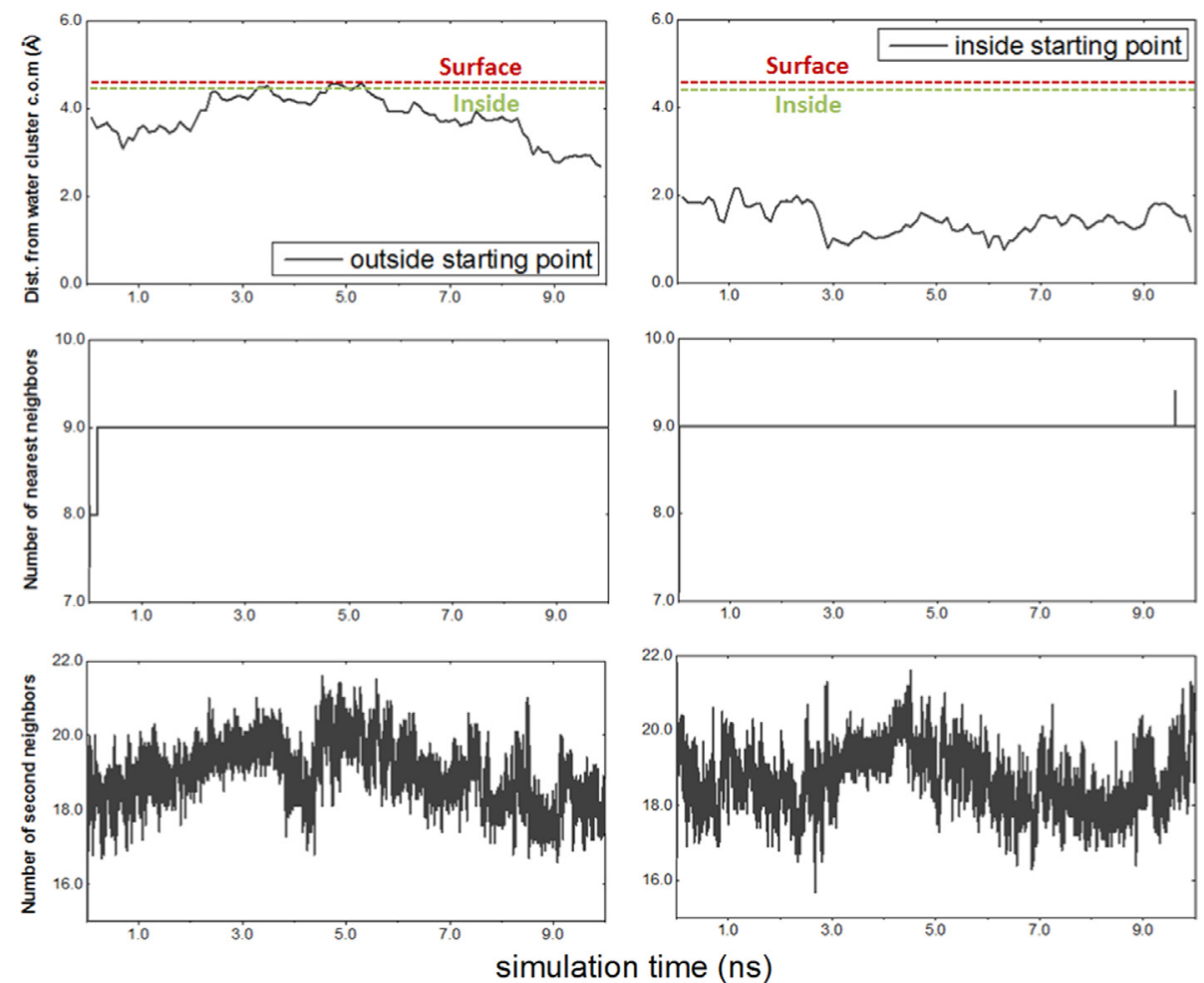

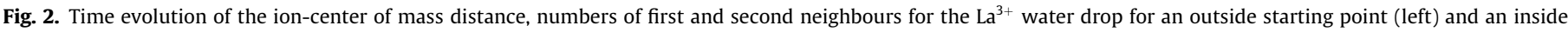
starting point (right). See text for details. 

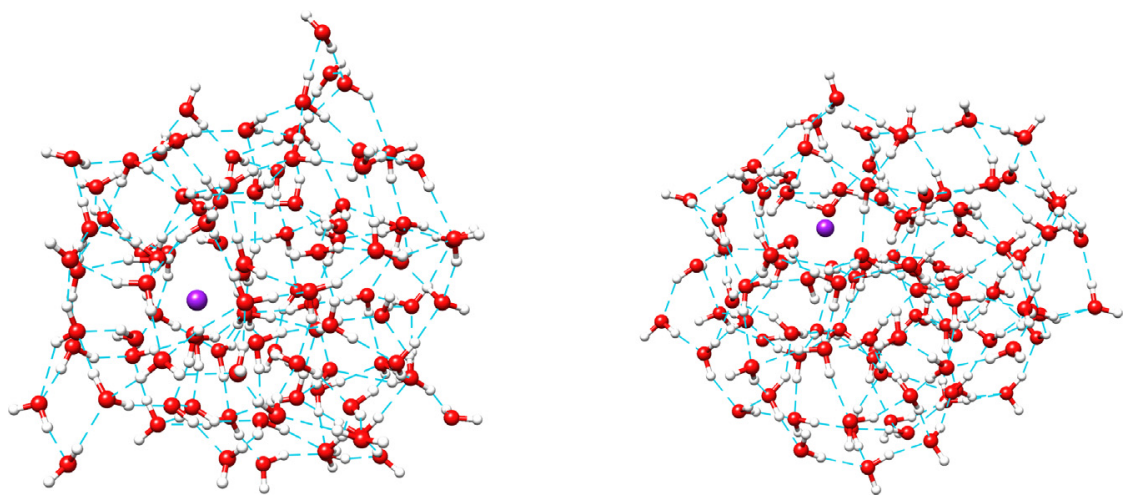

Fig. 3. Snapshots of final structures from different simulations for the $\mathrm{Ca}^{2+}$ water drop.

mean $\mathrm{CN}$ is 5.9 , with a $\mathrm{Na}-\mathrm{O}$ distance of $2.45 \AA$ in the first coordination sphere, and small fluctuations in the number of second neighbours around 17 water molecules. For $\mathrm{K}^{+}$and $\mathrm{Cs}^{+}$, the depopulation of the second shell, and even of the first shell, is observed during both types of simulation with large fluctuations of the numbers of first and second neighbours around the cation (Fig. 4). The mean $\mathrm{CN}$ are ca. 6.2 and 7.9 for $\mathrm{K}^{+}$and $\mathrm{Cs}^{+}$, respectively, computed from the inside starting point simulations.

In the anions series, the sulfate ion is fully solvated with an average of 12 neighbours organized with 3 water molecules hydrogen bound to each sulfate oxygens. The simulations indicate a mean $\mathrm{O}_{w}-\mathrm{O}_{\text {sulfate }}$ distance of ca. $3.85 \AA$. In contrast, the second shell is sometimes partly depopulated, which may be an effect of the size of the $\mathrm{SO}_{4}^{2-}$ ion with respect to the size of the cluster.

$\mathrm{F}^{-}$, the smallest anion, is mainly solvated by two complete solvation shells inside the cluster despite few hundreds of picoseconds (out of $10 \mathrm{~ns}$ ) spent at the surface with a depopulated second shell. The consequence is a fluctuation of the coordination number with an average value of 5.9 and a mean $\mathrm{F}-\mathrm{O}$ distance of ca. $2.84 \AA$. With chloride, we observe the first behavior of an ion positioning at the surface of the cluster (Fig. 5), suggesting that water-water are stronger than ion-water interactions. Its high polarization favors its position at the surface with partly filled solvation spheres and fluctuations in the number of first and second neighbours (4-6 and 8-15, respectively). The radial distribution function of the chloride ion highlights an important number of water exchanges between the two solvation spheres when $\mathrm{Cl}^{-}$is inside the drop, and a stability of the water network when it is at the surface. $\mathrm{Br}^{-}$has a similar behavior with a quick migration of the anion at the surface of the aggregate and an average $\mathrm{CN}$ of 5.0 was obtained for both anions.

In summary, small atomic anions are mainly solvated while the bigger prefer to be at the surface. However, $\mathrm{SO}_{4}^{2-}$ is different, with a preference to be far from the interface. Its behavior is explained by
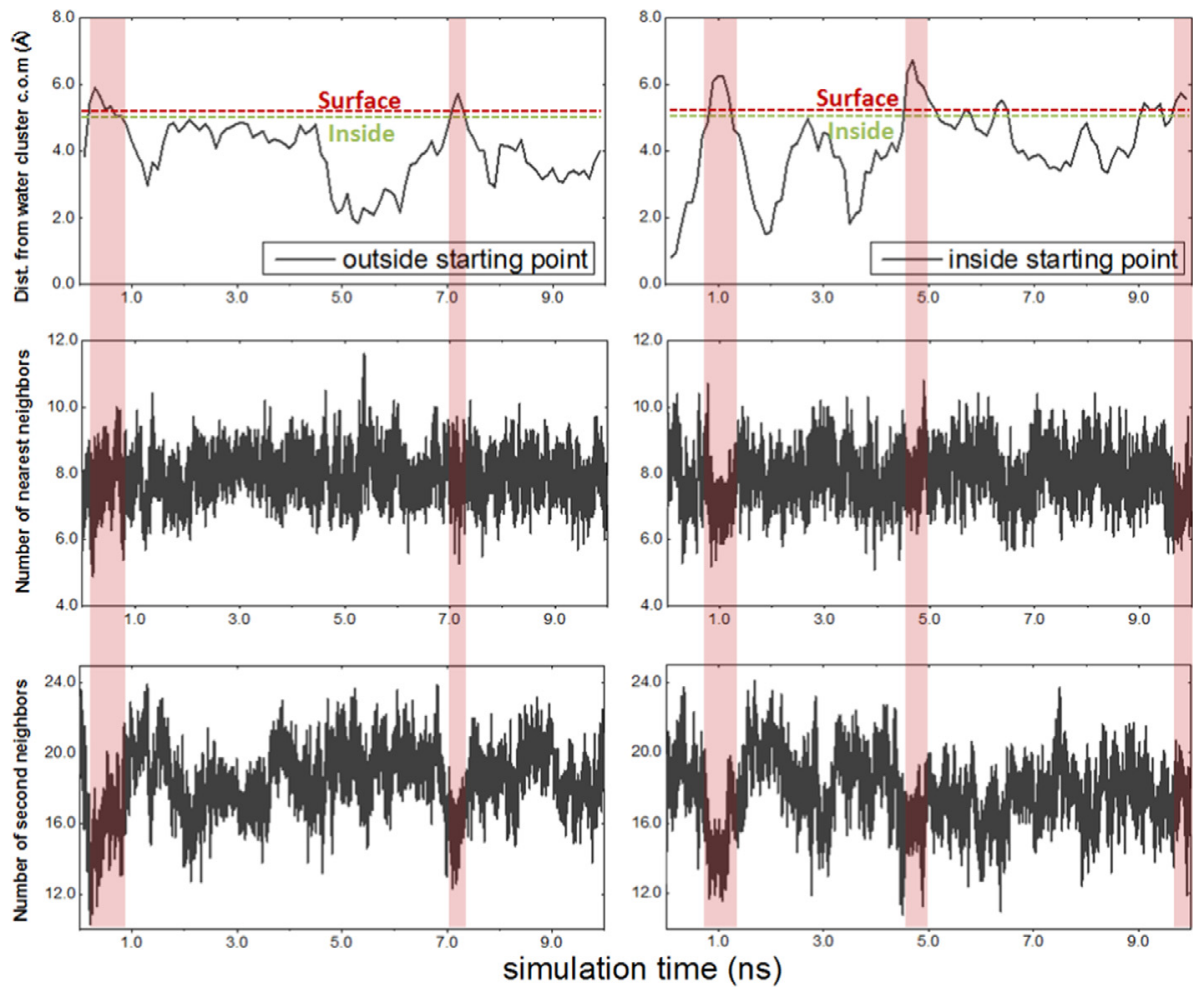

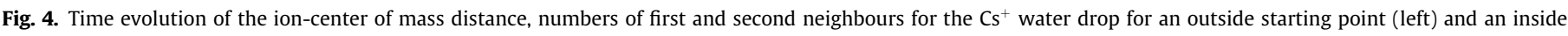
starting point (right). See text for details. 

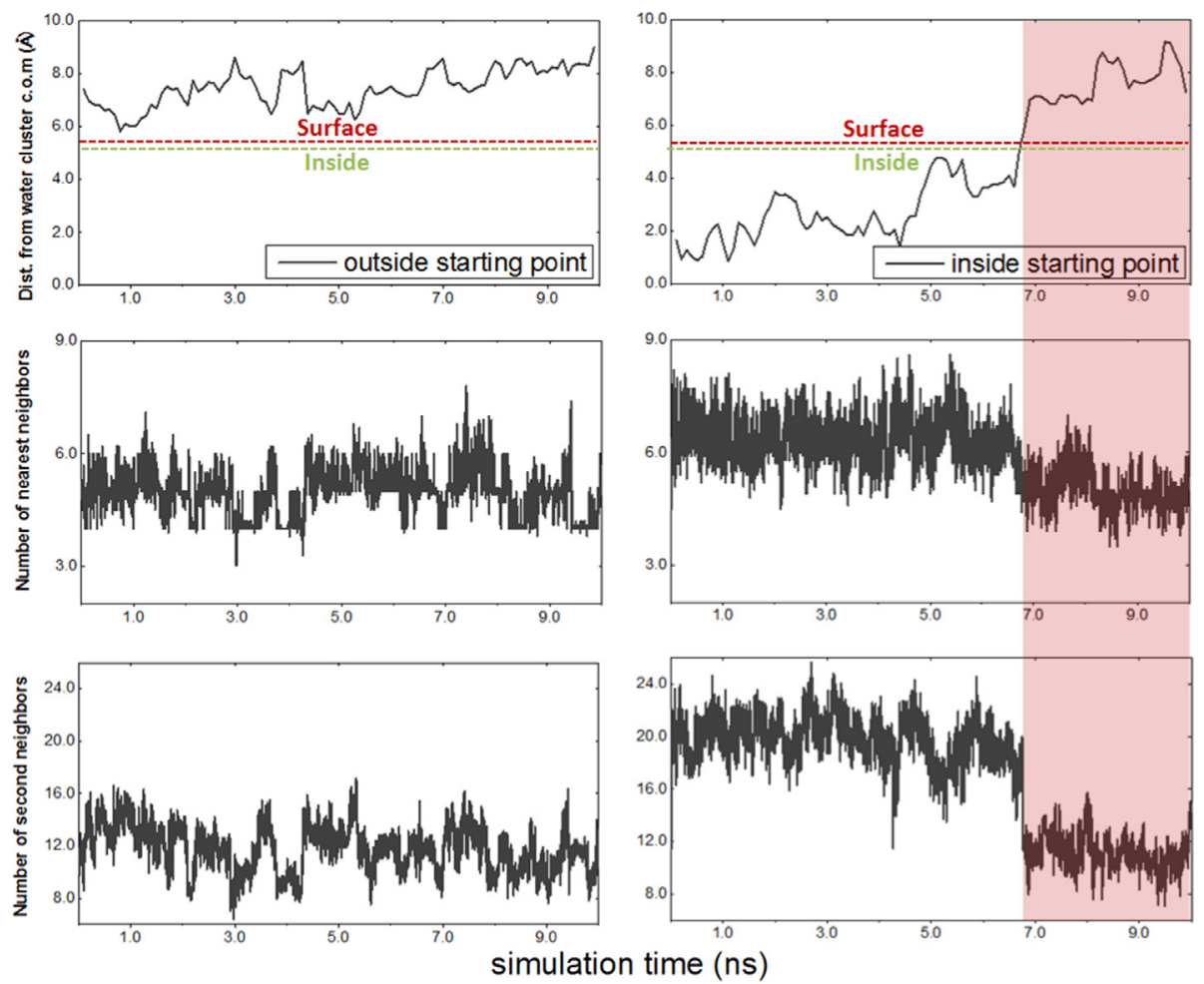

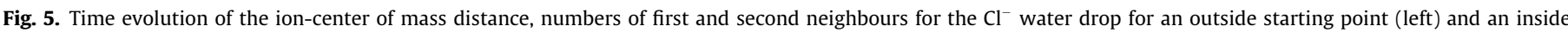
starting point (right). See text for details.

the large energetic penalty associated to the partial desolvation of the doubly charged anion at the surface [43].

\section{Conclusions}

Molecular dynamics simulations of ions in a water drop were carried out with the AMOEBA polarizable force field to (i) characterize their first two solvation shells, and (ii) capture their propensity to reside inside the cluster or to migrate from the center to the surface and conversely. For the cation series, the multiply-charged and small monovalent ions favor an inside position whereas the larger monovalent ions have a larger mobility and spend more time at the surface of the drop. The most structuring ions present a clear water organization around the cation with two and even three water shells. For the +3 and +2 cations, no or few exchanges have been observed during the simulations between water molecules in the first and second shells. Furthermore, the residence time decreases as the size of the monovalent cation increases. Regarding the anions, the results reproduce both the structuration of the solvent around the ion and the trend of the biggest ones to stay at the surface of the drop. This partial desolvation can be correlated to the ion size and polarizability. Residence times of water molecules in the first shell are predicted for the anion series. To conclude, the AMOEBA force field used without any reparametrization is able to provide accurate structural and dynamical properties for the whole series of ions under study.

\section{Acknowledgements}

F.T. thanks Ecole Polytechnique for a PhD fellowship. This work was granted access to the HPC resources of [CCRT/CINES/IDRIS] under the allocation c2015077128 made by GENCI (Grand Equipement National de Calcul Intensif).

\section{Appendix A. Supplementary material}

Supplementary data associated with this article can be found, in the online version, at http://dx.doi.org/10.1016/j.cplett.2017.01. 024.

\section{References}

[1] D.J. Tobias, J.C. Hemminger, Getting specific about specific ion effects, Science 319 (5867) (2008) 1197-1198.

[2] W. Kunz, J. Henle, B. Ninham, Zur Lehre von der Wirkung der Salze (about the science of the effect of salts): Franz Hofmeister's historical papers, Curr. Opin. Colloid Interface Sci. 9 (1-2) (2004) 19-37.

[3] M. Peschke, A.T. Blades, P. Kebarle, Hydration energies and entropies for $\mathrm{Mg}^{2+}$ $\mathrm{Ca}^{2+}, \mathrm{Sr}^{2+}$, and $\mathrm{Ba}^{2+}$ from gas-phase ion-water molecule equilibria determinations, J. Phys. Chem. A 102 (48) (1998) 9978-9985.

[4] M.T. Rodgers, P.B. Armentrout, Cationic noncovalent interactions: energetics and periodic trends, Chem. Rev. 116 (9) (2016) 5642-5687.

[5] P. Ayotte, C.G. Bailey, G.H. Weddle, M.A. Johnson, Vibrational spectroscopy of small $\mathrm{Br}^{-}\left(\mathrm{H}_{2} \mathrm{O}\right)_{n}$ and $\mathrm{I}^{-}\left(\mathrm{H}_{2} \mathrm{O}\right)_{n}$ clusters: infrared characterization of the ionic hydrogen bond, J. Phys. Chem. A 102 (18) (1998) 3067-3071.

[6] J.S. Prell, J.T. O’Brien, E.R. Williams, Structural and electric field effects of ions in aqueous nanodrops, J. Am. Chem. Soc. 133 (13) (2011) 4810-4818.

[7] J.T. O’Brien, E.R. Williams, Effects of ions on hydrogen-bonding water networks in large aqueous nanodrops, J. Am. Chem. Soc. 134 (24) (2012) 10228-10236.

[8] D.S. Lambrecht, L. McCaslin, S.S. Xantheas, E. Epifanovsky, M. Head-Gordon, Refined energetic ordering for sulfate-water $(n=3-6)$ clusters using high-level electronic structure calculations, Mol. Phys. 110 (19-20) (2012) 2513-2521.

[9] E. Cauët, S. Bogatko, J.H. Weare, J.L. Fulton, G.K. Schenter, E.J. Bylaska, Structure and dynamics of the hydration shells of the $\mathrm{Zn}^{2+}$ ion from ab initio molecular dynamics and combined ab initio and classical molecular dynamics simulations, J. Chem. Phys. 132 (19) (2010) 194502.

[10] Y. Zhao, H. Li, X.C. Zeng, First-principles molecular dynamics simulation of atmospherically relevant anion solvation in supercooled water droplet, J. Am. Chem. Soc. 135 (41) (2013) 15549-15558.

[11] S. Tazi, J.J. Molina, B. Rotenberg, P. Turq, R. Vuilleumier, M. Salanne, A transferable ab initio based force field for aqueous ions, J. Chem. Phys. 136 (11) (2012) 114507.

[12] T.-M. Chang, L.X. Dang, Recent advances in molecular simulations of ion solvation at liquid interfaces, Chem. Rev. 106 (4) (2006) 1305-1322.

[13] D. Semrouni, W.C. Isley, C. Clavaguéra, J.-P. Dognon, C.J. Cramer, L. Gagliardi, $\mathrm{Ab}$ initio extension of the AMOEBA polarizable force field to $\mathrm{Fe}^{2+}, \mathrm{J}$. Chem. Theor. Comput. 9 (7) (2013) 3062-3071. 
[14] J.C. Wu, J.-P. Piquemal, R. Chaudret, P. Reinhardt, P. Ren, Polarizable molecular dynamics simulation of $\mathrm{Zn}(\mathrm{II})$ in water using the AMOEBA force field, J. Chem. Theor. Comput. 6 (7) (2010) 2059-2070.

[15] J.-P. Piquemal, L. Perera, G.A. Cisneros, P. Ren, L.G. Pedersen, T.A. Darden, Towards accurate solvation dynamics of divalent cations in water using the polarizable AMOEBA force field: from energetics to structure, J. Chem. Phys. 125 (5) (2006) 054511.

[16] P. D’Angelo, R. Spezia, Hydration of Lanthanoids(III) and Actinoids(III): an experimental/theoretical saga, Chem. Eur. J. 18 (36) (2012) 11162-11178.

[17] K.J. Tielrooij, N. Garcia-Araez, M. Bonn, H.J. Bakker, Cooperativity in ion hydration, Science 328 (5981) (2010) 1006-1009.

[18] J.S. Prell, E.R. Williams, Structures of thermal, mass-selected water clusters probed with hydrophobic ion tags and infrared photodissociation spectroscopy, J. Am. Chem. Soc. 131 (11) (2009) 4110-4119.

[19] J.-H. Choi, K.T. Kuwata, Y.-B. Cao, M. Okumura, Vibrational spectroscopy of the $\mathrm{Cl}^{-}\left(\mathrm{H}_{2} \mathrm{O}\right)_{n}$ anionic clusters, $n=1-5$, J. Phys. Chem. A 102 (3) (1998) 503-507.

[20] J.W. Caldwell, P.A. Kollman, Ab initio calculations on aquated chloride $\left(\mathrm{Cl}^{-}\left(\mathrm{H}_{2} \mathrm{O}\right)_{14}\right)$ clusters: comparison with the results from molecular dynamics simulations, J. Phys. Chem. 96 (21) (1992) 8249-8251.

[21] L. Perera, M.L. Berkowitz, Structure and dynamics of $\mathrm{Cl}^{-}\left(\mathrm{H}_{2} \mathrm{O}\right)_{20}$ clusters: the effect of the polarizability and the charge of the ion, J. Chem. Phys. 96 (11) (1992) 8288-8294.

[22] L.X. Dang, J.E. Rice, J. Caldwell, P.A. Kollman, Ion solvation in polarizable water: molecular dynamics simulations, J. Am. Chem. Soc. 113 (7) (1991) 2481-2486.

[23] E.M. Knipping et al., Experiments and simulations of ion-enhanced interfacia chemistry on aqueous $\mathrm{NaCl}$ aerosols, Science 288 (5464) (2000) 301-306.

[24] E.C. Brown, M. Mucha, P. Jungwirth, D.J. Tobias, Structure and vibrational spectroscopy of salt water/air interfaces: predictions from classical molecular dynamics simulations, J. Phys. Chem. B 109 (16) (2005) 7934-7940.

[25] C. Caleman, J.S. Hub, P.J. van Maaren, D. van der Spoel, Atomistic simulation of ion solvation in water explains surface preference of halides, Proc. Natl. Acad. Sci. 108 (17) (2011) 6838-6842.

[26] D.M. Koch, G.H. Peslherbe, On the transition from surface to interior solvation in iodide-water clusters, Chem. Phys. Lett. 359 (5-6) (2002) 381-389.

[27] L. Perera, M.L. Berkowitz, Many-body effects in molecular dynamics simulations of $\mathrm{Na}^{+}\left(\mathrm{H}_{2} \mathrm{O}\right)_{n}$ and $\mathrm{Cl}^{-}\left(\mathrm{H}_{2} \mathrm{O}\right)_{n}$ clusters, J. Chem. Phys. 95 (3) (1991) 1954-1963.

[28] P. Ren, J.W. Ponder, Polarizable atomic multipole water model for molecular mechanics simulation, J. Phys. Chem. B 107 (24) (2003) 5933-5947.

[29] A. Grossfield, P. Ren, J.W. Ponder, Ion solvation thermodynamics from simulation with a polarizable force field, J. Am. Chem. Soc. 125 (50) (2003) $15671-15682$.

[30] L. Tủma, D. Jeníček, P. Jungwirth, Propensity of heavier halides for the water/vapor interface revisited using the Amoeba force field, Chem. Phys. Lett. $411(1-3)(2005) 70-74$.

[31] C. Jana, G. Ohanessian, C. Clavaguéra, Theoretical insight into the coordination number of hydrated $\mathrm{Zn}^{2+}$ from gas phase to solution, Theor. Chem. Acc. 135 (5) (2016) 1-13.

[32] A. Marjolin, C. Gourlaouen, C. Clavaguéra, P.Y. Ren, J.-P. Piquemal, J.-P. Dognon, Hydration gibbs free energies of open and closed shell trivalent lanthanide and actinide cations from polarizable molecular dynamics, J. Mol. Mod. 20 (2014) 2471.

[33] J.W. Ponder, TINKER - Software Tools for Molecular Design, version 6, Washington University School of Medicine, Saint Louis, USA, 2013. $<$ http://dasher.wustl.edu/tinker>.

[34] A. Müller, H. Bögge, E. Diemann, Structure of a cavity-encapsulated nanodrop of water, Inorg. Chem. Comm. 6 (1) (2003) 52-53.

[35] R.W. Impey, P.A. Madden, I.R. McDonald, Hydration and mobility of ions in solution, J. Phys. Chem. 87 (25) (1983) 5071-5083.

[36] H. Ohtaki, T. Radnai, Structure and dynamics of hydrated ions, Chem. Rev. 93 (3) (1993) 1157-1204.

[37] P.R. Smirnov, V.N. Trostin, Structural parameters of the nearest surrounding of lanthanide ions in aqueous solutions of their salts, Russ. J. Gen. Chem. 82 (3) (2012) 360-378.

[38] Y.S. Badyal, A.C. Barnes, G.J. Cuello, J.M. Simonson, Understanding the effects of concentration on the solvation structure of $\mathrm{Ca}^{2+}$ in aqueous solution. II: Insights into longer range order from neutron diffraction isotope substitution, J. Phys. Chem. A 108 (52) (2004) 11819-11827.

[39] F. Jalilehvand, D. Spångberg, P. Lindqvist-Reis, K. Hermansson, I. Persson, M. Sandström, Hydration of the calcium ion. An EXAFS, large-angle X-ray scattering, and molecular dynamics simulation study, J. Am. Chem. Soc. 123 (3) (2001) 431-441.

[40] P.S. Salmon, W.S. Howells, R. Mills, The dynamics of water molecules in ionic solution. II. Quasi-elastic neutron scattering and tracer diffusion studies of the proton and ion dynamics in concentrated $\mathrm{Ni}^{2+}, \mathrm{Cu}^{2+}$ and $\mathrm{Nd}^{3+}$ aqueous solutions, J. Phys. C: Solid State Phys. 20 (34) (1987) 5727.

[41] D. Laage, J.T. Hynes, On the residence time for water in a solute hydration shell: application to aqueous halide solutions, J. Phys. Chem. B 112 (26) (2008) 7697-7701.

[42] S. Diaz-Moreno, S. Ramos, D.T. Bowron, Solvation structure and ion complexation of $\mathrm{La}^{3+}$ in a 1 molal aqueous solution of lanthanum chloride, J. Phys. Chem. A 115 (24) (2011) 6575-6581.

[43] P. Jungwirth, J.E. Curtis, D.J. Tobias, Polarizability and aqueous solvation of the sulfate dianion, Chem. Phys. Lett. 367 (5-6) (2003) 704-710.

[44] J. Mähler, I. Persson, A study of the hydration of the alkali metal ions in aqueous solution, Inorg. Chem. 51 (1) (2012) 425-438.

[45] A.T. Blades, P. Kebarle, Sequential hydration energies of the sulfate ion, from determinations of the equilibrium constants for the gas-phase reactions: $\mathrm{SO}_{4}\left(\mathrm{H}_{2} \mathrm{O}\right)_{n}^{2-}=\mathrm{SO}_{4}\left(\mathrm{H}_{2} \mathrm{O}\right)_{n-1}^{2-}+\mathrm{H}_{2} \mathrm{O}$, J. Phys. Chem. A 109 (37) (2005) 82938298.

[46] R.L. Wong, E.R. Williams, Dissociation of $\mathrm{SO}_{4}^{2-}\left(\mathrm{H}_{2} \mathrm{O}\right)_{n}$ clusters, $n=3-17$, J. Phys. Chem. A 107 (50) (2003) 10976-10983.

[47] L. Helm, A.E. Merbach, Inorganic and bioinorganic solvent exchange mechanisms, Chem. Rev. 105 (6) (2005) 1923-1960.

[48] M. Eigen, Fast elementary steps in chemical reaction mechanisms, Pure Appl. Chem. 6 (1963) 97-116.

[49] D.T. Richens, The chemistry of aqua ions: synthesis, structure and reactivity: a tour through the periodic table of the elements, Wiley, 1997, ISBN: 978-0-47197058-3. 